\title{
Elevated Serum Fibrin-Monomer Levels are Associated With High Long-Term Cerebrovascular Event Rates in Acute Ischemic Stroke Patients
}

\author{
Harutoshi Tamura, MD; Osamu Hirono, MD; Hidenobu Okuyama, MD; \\ Ling Liu, MD; Satoshi Nishiyama, MD; Yasuchika Takeishi, MD; \\ Takamasa Kayama, MD*; Isao Kubota, MD
}

\begin{abstract}
Background Serum fibrin-monomer (FM) is a precursor of stable fibrin, and is a sensitive marker of a systemic hypercoagulable state. It has been reported that, in patients with acute ischemic stroke, higher levels of serum FM reflect intracardiac thrombus formation.

Methods and Results Serum coagulation and fibrinolytic activity were measured in 113 patients with acute ischemic stroke within $7(6 \pm 1)$ days after onset. The patients were followed for a mean of 354 (range 36-585) days. The primary endpoints were ischemic stroke recurrence with/without death. FM was markedly higher in the 19 cases with stroke recurrence $(49.6 \pm 53.6 \mu \mathrm{g} / \mathrm{ml})$ than in the 94 patients without stroke recurrence $(14.6 \pm$ $30.5 \mu \mathrm{g} / \mathrm{ml} ; \mathrm{p}=0.008$ ). The cerebrovascular event rates were markedly higher in the 12 cases with $\mathrm{FM} \geq 16.5 \mu \mathrm{g} / \mathrm{ml}$ $(37.5 \%)$ than in the 7 cases with FM $<16.5 \mu \mathrm{g} / \mathrm{ml}(8.6 \%$; $\mathrm{p}<0.001)$. Cox proportional hazards multivariate analysis showed that the FM level was an independent predictor of ischemic stroke recurrence with/without death (hazard ratio, 1.516 per +1 standard deviation increase; 95\% confidence interval, 1.042-2.180; $\mathrm{p}=0.036$ ).

Conclusions Elevated serum FM levels in hospitalized ischemic stroke patients may be associated with a persistent systemic hypercoagulable state and high long-term rates of cerebrovascular events. (Circ J 2007; 71: $1573-1579)$
\end{abstract}

Key Words: Acute ischemic stroke; Fibrin-monomer; Prognosis

I t has been noticed that serum fibrin-monomer (FM), which is produced by the thrombin-mediated resolution of fibrinopeptide A from fibrinogen, is a new marker for systemic thrombus occurrence. Compared with fibrin polymer and stable fibrin, FM is fragile in vivo, because of fibrinolysis, so it is thought to be a sensitive marker of a hypercoagulable state!-3 Compared with other routine thromboembolic markers, the FM level has been demonstrated to be an independent predictor of systemic thrombus occurrence and to be a useful screening tool for identifying older individuals at increased risk of stroke,.5 Furthermore, it has been reported that, in acute ischemic stroke patients, higher FM levels are directly associated with flow pattern alterations and thrombus formation in the left atrial appendage! It is well known that, during the acute period, cardioembolic stroke cases lack the systemic balance between coagulability and fibrinolytic activity. Thus, plasma thrombin-antithrombin complex and D-dimer concentrations are useful indicators of the risk of recurrent

(Received December 22, 2006; revised manuscript received June 11, 2007; accepted July 3, 2007)

Department of Cardiology, Pulmonology, and Nephrology, *Department of Neurosurgery, Yamagata University School of Medicine, Yamagata, Japan

This work was presented at the 79 ${ }^{\text {th }}$ Annual Scientific Sessions of the American Heart Association, Chicago, IL, November 2006, and supported in part by a grant from the Ministry of Education, Culture, Sports, Science and Technology, Japan (No. 17590704).

Mailing address: Osamu Hirono, MD, Department of Cardiology, Pulmonology, and Nephrology, Yamagata University School of Medicine, 2-2-2 Iida-nishi, Yamagata 990-9585, Japan. E-mail: ohirono@med. id.yamagata-u.ac.jp embolization, 6,7 On the other hand, it is unknown whether elevated FM levels are directly related to long-term ischemic stroke recurrence.

In recent years, many interventional treatment strategies, such as intravenous infusion of thrombolytic agents, carotid arterial stenting, or closure of a patent foramen ovale, have been used to prevent enlargement of the infarcted area and recurrent attacks. However, ischemic cerebral stroke is 1 of the most frequent causes of disability and, compared with other cardiovascular diseases, its recurrence rate remains high (10-20\%/year) $)^{8,9}$ It is important to identify a sensitive serum marker that can predict long-term ischemic stroke recurrence and/or death at the onset of cerebral infarction.

The goal of this study was to investigate the association between the acute phase serum FM level and long-term cerebrovascular events in ischemic stroke patients.

\section{Methods}

Study Patients

Of 137 consecutive patients with acute cerebral infarction, 113 satisfied all of the following criteria and were enrolled: (1) abrupt stroke onset while awake with a maximal neurological deficit; (2) admission within $24 \mathrm{~h}$ of symptom recognition; (3) measurements of serum coagulation and fibrinolytic activity, as well as transesophageal echocardiography, were done within $7(6 \pm 1)$ days of onset; (4) not treated with intravenous infusion of thrombolytic agents or heparin; and (5) no cancer, disseminated intravascular coagulation, and/or infectious diseases within the week preceding the stroke. The admission assessment in- 
cluded determining the risk factors for cerebral infarction, clinical ischemic stroke categories (US National Institute of Neurological Disorders and Stroke) ${ }^{10}$ and disease severity using the US National Institute of Health Stroke Scale (NIHSS) 11 On admission, all patients underwent cerebral computed tomography and/or magnetic resonance imaging, as well as continuous ECG monitoring to determine their cardiac rhythms; all patients were treated according to a standardized protocol for the management of dehydration, hyperglycemia, hypoxia, and pyrexia. The study subjects were classified into 2 groups based on the presence of ischemic stroke recurrence with/without death during the mean follow-up of 354 \pm 111 (range, 36-585) days (cases with ischemic stroke recurrence with/without death, $n=19$, age $72 \pm 14$ years; cases with no events, $n=94$, age $71 \pm 11$ years). Serum coagulation and fibrinolytic activity of the 2 groups were compared retrospectively, and the relevant serum FM cut-off values for predicting long-term cerebrovascular events were determined using the receiver-operating characteristic (ROC) curve, as previously reported ${ }^{12}$ The local ethics committee approved the study protocol, and written informed consent was given by all subjects.

\section{Echocardiography}

Transthoracic echocardiography was done using a Hewlett Packard SONOS 7500 ultrasound machine equipped with a sector transducer (carrier frequency of 2.5 or $3.75 \mathrm{MHz}$ ). A 5-MHz phased-array multiplane probe was used for transesophageal echocardiography. Using standard views and techniques, left atrial dimensions, left ventricular end-diastolic dimensions, and left ventricular percent fractional shortening were measured, and the presence of an atrial septal aneurysm, patent foramen ovale, spontaneous echocardiographic contrast, and intracardiac thrombus formation were determined,13-15 The left atrial appendage emptying flow velocity at atrial systole was assessed on pulsed-wave Doppler with the sample volume placed $1 \mathrm{~cm}$ distal from the mouth of the appendage, and the maximum velocity was obtained by scanning the appendage at 0-90 degrees! 16,17

\section{Aortic and Carotid Echocardiographic Studies}

Aortic images were obtained during transesophageal echocardiography after the cardiac examination. The depth was set at $5 \mathrm{~cm}$, and the transducer was slowly withdrawn from the level of the distal thoracic aorta to the aortic arch in the transverse plane. Maximal intima-media thickness of the aortic arch without protruding atheromatous plaque was measured at end-diastole if the intima-medial layer was continuously visible. The prevalence of protrusion $>5 \mathrm{~mm}$ and/or mobile plaque in the arch was determined 18,19

Bilateral carotid artery imaging was performed with a 7.5-MHz linear transducer connected to a SONOS 7500 system. Longitudinal images of the bilateral common and proximal internal carotid arteries (and their bifurcations) were obtained. The carotid intima-medial thickness without protruding atheromatous plaques was measured at enddiastole according to the method of Pignoli et al, and was obtained as the mean of the bilateral common carotid arteries ${ }^{20}$ The luminal percentage stenosis at the site of maximal narrowing on the side responsible for the infarction was calculated according to the European Carotid Surgery Trial method; stenosis $>50 \%$ was defined as a significant carotid plaque lesion. 21,22

All echocardiographic measurements were taken as the mean of 5 consecutive cardiac cycles. The identification of intracardiac thrombus was performed offline, and all findings were evaluated by 2 independent, blinded, experienced echocardiologists (H.T. and O.H.).

\section{Hemostatic Markers}

Blood samples were taken to determine the serum hemostatic marker levels at the time of the echocardiographic studies and stored at $-80^{\circ} \mathrm{C}$ until processing. Antithrombin III, thrombin-antithrombin complex, fibrinogen, and FM were assessed as indices of coagulation; plasminogen, plasmin activator inhibitor-1, a 2-plasmin inhibitor, and plasmina 2-plasmin inhibitor complex were assessed as indices of fibrinolysis; and fibrinogen degradation products and D-dimer were assessed as products of fibrinogen resolution and stable fibrin. General biochemical parameters were measured using routine laboratory methods. The normal upper limits (or ranges) for these markers in our laboratory were as follows: antithrombin III, 75-125\%; thrombin-antithrombin complex, <3.0 ng/ml; fibrinogen, $150-400 \mathrm{mg} / \mathrm{dl}$; plasminogen, 75-125\%; plasmin activator inhibitor-1, $<50 \mathrm{ng} / \mathrm{ml}$; a 2-plasmin inhibitor, 75-125\%; plasmina 2plasmin inhibitor complex, $<0.8 \mathrm{ng} / \mathrm{ml}$; fibrinogen degradation products, $<5.9 \mu \mathrm{g} / \mathrm{ml}$; and D-dimer, $0.1-1.0 \mu \mathrm{g} / \mathrm{ml}$. The serum FM level was measured using an enzyme-linked immunosorbent assay as reported previously; the normal upper limit was $6.1 \mu \mathrm{g} / \mathrm{ml}^{23}$ In addition, in 14 patients not on any anticoagulant therapies and no recurrent events ( $72 \pm 20$ years old), the serum FM level was determined at the time of stroke onset (day 1), as well as on 7 and 14 days after admission.

\section{Endpoints and Follow-up}

The mean follow-up period was $354 \pm 111$ days (range, 36-585 days) after admission to Yamagata University Hospital. Events were adjudicated using medical records, autopsy reports, death certificates, and witness statements. The endpoints, which were judged independently by the researchers, were cerebrovascular death and recurrent ischemic stroke requiring readmission.

\section{Statistical Analysis}

Results are expressed as mean \pm standard deviation (SD) for continuous variables and as the percentage of total patients for categorical variables. Statistical analysis was conducted using a standard statistical program package (Stat View, version 5.0, SAS Institute Inc, Cary, NC, USA). Patient characteristics, echocardiographic parameters, and hemostatic markers were compared between patients with ischemic stroke recurrence (Event $(+)$ ) and without events (Event (-)) using the Mann-Whitney U-test for continuous variables and the chi-square test for categorical variables. In the 14 patients who were not on anticoagulant therapy and had no recurrent events, serum FM levels at the time of stroke onset (on admission) and at 7 or 14 days after admission were compared using Student's t-test for paired variables. Cox proportional hazards analysis was performed to determine the independent serum predictor of ischemic stroke recurrent events for the entire population. Significant variables selected on univariate analysis were entered into the multivariate analysis. The univariate regression analysis was used for comparisons of serum FM levels on admission and other homeostatic markers. The ROC curve was constructed to determine the relevant FM cut-off values for predicting cerebrovascular events at 354 (36-585) days based on the optimal sensitivity and specificity!2 The area 
Table 1 Clinical Characteristics of the Study Subjects

\begin{tabular}{lccc}
\hline \hline & $\begin{array}{c}\text { Event }(+) \\
(n=19)\end{array}$ & $\begin{array}{c}\text { Event }(-) \\
(n=94)\end{array}$ & $p$ value \\
\hline Age (years) & $72 \pm 14$ & $71 \pm 11$ & $N S$ \\
Gender $(M / F)$ & $11 / 8$ & $62 / 32$ & $N S$ \\
$H R($ beats/min) & $80 \pm 19$ & $73 \pm 18$ & $N S$ \\
AF & $9(47.3 \%)$ & $32(34.0 \%)$ & $N S$ \\
$H T$ & $14(73.7 \%)$ & $76(80.9 \%)$ & $N S$ \\
DM & $5(26.3 \%)$ & $18(19.1 \%)$ & $N S$ \\
HL & $7(36.8 \%)$ & $36(38.3 \%)$ & $N S$ \\
Current smoker & $9(47.3 \%)$ & $46(50.0 \%)$ & $N S$ \\
Previous stroke & $9(47.3 \%)$ & $33(35.1 \%)$ & $N S$ \\
NIHSS & $5.4 \pm 8.3$ & $6.2 \pm 7.4$ & $N S$ \\
NINDS clinical categories & & & \\
Atherothrombotic & $8(42.1 \%)$ & $41(43.6 \%)$ & $N S$ \\
Cardioembolic & $7(36.8 \%)$ & $23(24.5 \%)$ & $N S$ \\
Lacunar & $3(15.8 \%)$ & $26(27.7 \%)$ & $N S$ \\
Other & $1(5.3 \%)$ & $4(4.3 \%)$ & $N S$ \\
Oral medications (after onset) & & & \\
Antiplatelets & $7(36.8 \%)$ & $35(37.2 \%)$ & NS \\
Anticoagulants & $5(26.3 \%)$ & $13(13.8 \%)$ & NS \\
An & &
\end{tabular}

All data are mean \pm standard deviation or number of subjects.

Event (+), cases with ischemic stroke recurrence with/without death; Event (-), cases with no events; HR, heart rate; AF, atrial fibrillation; HT, hypertension; DM, diabetes mellitus; HL, hyperlipidemia; NIHSS, National Institute of Health Stroke Scale; NINDS, clinical categories of brain infarction from the National Institute of Neurological Disorders and Stroke.

under the curve was calculated by the trapezoidal rule. The cerebrovascular event-free curve was prepared according to the Kaplan-Meier method, and the log-rank test was used to compare the cerebrovascular event-free survival of the subgroups classified by the optimal FM values determined using the ROC curve. P-values less than 0.05 were considered significant.

\section{Results}

\section{Patient's Characteristics}

There were 19 cerebrovascular events (16 readmissions, 3 deaths) during the follow-up period. The clinical characteristics of patients with and without events were compared (Table 1). There were no significant differences between the 2 groups with respect to age, gender, heart rate, prevalence of atrial fibrillation, hypertension, diabetes mellitus, hyperlipidemia, history of previous stroke, NIH stroke scale, clinical stroke categories, and the use of oral antithrombotic medications.

\section{Clinical Outcomes}

None of the patients was lost to follow-up. There were 8 non-cerebrovascular deaths (3 gastric cancer, 1 lung cancer, 1 pancreatic cancer, and 3 pneumonia), and 19 patients had ischemic stroke recurrence requiring readmission with/without causing death (16.8\%); no patient had ischemic heart disease during follow-up. Of the 19 cerebrovascular events, $16(84.2 \%)$ occurred within 12 months after initial admission. All 19 patients were readmitted for ischemic cerebrovascular events ( 5 had total anterior circulation involvement, 8 had partial anterior circulation involvement, 3 had posterior circulation involvement, 2 had transient ischemic attacks, and 1 had right brachial arterial thromboembolism); there were 3 cerebrovascular deaths.

\section{Echocardiographic Parameters}

There were no significant differences between the 2
Table 2 Echocardiographic Findings

\begin{tabular}{lccc}
\hline \hline & Event $(+)$ & Event $(-)$ & p value \\
\hline LAD $(\mathrm{mm})$ & $40 \pm 6$ & $39 \pm 6$ & $N S$ \\
LVDd $(\mathrm{mm})$ & $47 \pm 6$ & $48 \pm 6$ & $N S$ \\
LVFS $(\%)$ & $32 \pm 6$ & $35 \pm 8$ & $N S$ \\
LAA $\mathrm{eV}(\mathrm{cm} / \mathrm{s})$ & $42 \pm 26$ & $49 \pm 30$ & $\mathrm{NS}$ \\
SEC & $6(31.6 \%)$ & $20(21.3 \%)$ & $\mathrm{NS}$ \\
Thrombus & $5(26.3 \%)$ & $13(13.8 \%)$ & $\mathrm{NS}$ \\
ASA & $4(21.1 \%)$ & $13(13.8 \%)$ & $\mathrm{NS}$ \\
PFO & $1(5.3 \%)$ & $8(8.5 \%)$ & $\mathrm{NS}$ \\
Aortic plaque & $8(42.1 \%)$ & $23(24.4 \%)$ & $\mathrm{NS}$ \\
Aortic IMT $(\mathrm{mm})$ & $3.6 \pm 1.7$ & $3.2 \pm 1.4$ & $\mathrm{NS}$ \\
Carotid plaque & $5(26.3 \%)$ & $15(16.0 \%)$ & $\mathrm{NS}$ \\
Carotid IMT $(\mathrm{mm})$ & $0.8 \pm 0.2$ & $0.8 \pm 0.2$ & $\mathrm{NS}$ \\
\hline
\end{tabular}

All data are mean \pm standard deviation or number of subjects.

$L A D$, left atrial dimension; $L V D d$, left ventricular end-diastolic dimension; $L V F S$, left ventricular percent fractional shortening; LAA $\mathrm{eV}$, left atrial appendage emptying flow velocity at atrial systole; SEC, spontaneous echo contrast; Thrombus, intracardiac thrombus formation; ASA, atrial septal aneurysm; PFO, patent foramen ovale; Aortic plaque, protruding $>5 \mathrm{~mm}$ and/or mobile plaques in the aortic arch; IMT, intima-media thickness; Carotid plaque, protruding plaque with $>50 \%$ luminal stenosis in the common and/or proximal internal carotid artery. Other abbreviations as in Table 1.

Table 3 Haemostatic Markers in Cases With and Without Recurrent Events

\begin{tabular}{lccc}
\hline \hline & Event $(+)$ & Event $(-)$ & p value \\
\hline CRP $(\mathrm{mg} / \mathrm{dl})$ & $3.3 \pm 5.5$ & $1.6 \pm 2.6$ & 0.030 \\
AT III $(\%)$ & $107 \pm 16$ & $106 \pm 18$ & $\mathrm{NS}$ \\
TAT $(\mathrm{ng} / \mathrm{ml})$ & $13.8 \pm 13.8$ & $11.8 \pm 12.1$ & $\mathrm{NS}$ \\
Fibrinogen $(\mathrm{mg} / \mathrm{dl})$ & $456 \pm 234$ & $429 \pm 159$ & $\mathrm{NS}$ \\
FM $(\mu \mathrm{g} / \mathrm{ml})$ & $49.6 \pm 53.6$ & $14.6 \pm 30.5$ & 0.008 \\
Plasminogen $(\%)$ & $101 \pm 34$ & $98 \pm 19$ & $\mathrm{NS}$ \\
PAI-1 $(\mathrm{ng} / \mathrm{ml})$ & $16.2 \pm 10.1$ & $15.7 \pm 9.8$ & $\mathrm{NS}$ \\
a 2-PI $(\%)$ & $110 \pm 23$ & $108 \pm 16$ & $\mathrm{NS}$ \\
PIC $(\mathrm{ng} / \mathrm{ml})$ & $1.9 \pm 1.0$ & $1.4 \pm 1.0$ & 0.046 \\
D-dimer $(\mu \mathrm{g} / \mathrm{ml})$ & $4.7 \pm 1.1$ & $2.4 \pm 3.3$ & 0.031 \\
FDP $(\mu \mathrm{g} / \mathrm{ml})$ & $9.1 \pm 7.4$ & $5.0 \pm 5.2$ & $\mathrm{NS}$ \\
\hline
\end{tabular}

All data are mean \pm standard deviation.

CRP, C-reactive protein; AT III, antithrombin III; TAT, thrombin-antithrombin complex; FM, fibrin-monomer; PAI-1, plasmin activator inhibitor-1; a 2-PI, a 2-plasmin inhibitor; PIC, plasmina 2PI complex; FDP, fibrinogen degradation product. Other abbreviations as in Table 1.

groups with respect to left atrial and ventricular end-diastolic dimensions, systolic fractional shortening, left atrial appendage emptying flow velocity, aortic or carotid intimamedia thickness, and the prevalence of spontaneous echocardiographic contrast, intracardiac thrombus formation, atrial septal aneurysm, patent foramen ovale, and significant aortic or carotid atherosclerotic plaques (Table 2).

\section{Hemostatic Findings}

Compared with the patients with no events, patients with recurrent cerebrovascular events had higher levels of $\mathrm{C}$ reactive protein $(3.3 \pm 5.5$ vs $1.6 \pm 2.6 \mathrm{mg} / \mathrm{dl}, \mathrm{p}=0.030), \mathrm{FM}$ $(49.6 \pm 53.6$ vs $14.6 \pm 30.5 \mu \mathrm{g} / \mathrm{ml}, \mathrm{p}=0.008)$, plasmina $2-$ plasmin inhibitor complex $(1.9 \pm 1.0$ vs $1.4 \pm 1.0 \mathrm{ng} / \mathrm{ml}, \mathrm{p}=$ $0.046)$, and D-dimer $(4.7 \pm 1.1$ vs $2.4 \pm 3.3 \mu \mathrm{g} / \mathrm{ml}, \mathrm{p}=0.031)$ (Table 3). Furthermore, serum FM levels were significantly higher in patients with recurrent events than in those with no events, regardless of the presence of cardioembolic stroke, atrial fibrillation, or oral warfarin treatment (cardioembolic, $56.5 \pm 48.1$ vs $23.2 \pm 22.7 \mu \mathrm{g} / \mathrm{ml}, \mathrm{p}=0.032$; non-cardioembolic, $45.6 \pm 46.8$ vs $11.8 \pm 33.1 \mu \mathrm{g} / \mathrm{ml}, \mathrm{p}=0.020$; atrial fibrillation, 
Table 4 FM Levels in Cases With and Without Recurrent Events According to the Presence of Cardioembolic Stroke or AF

\begin{tabular}{lllc}
\hline \hline & \multicolumn{1}{c}{ Event $(+)$} & Event $(-)$ & $p$ value \\
\hline Cardioembolic & $56.5 \pm 65.2(7)$ & $23.2 \pm 22.7(23)$ & 0.032 \\
Non-cardioembolic & $45.6 \pm 46.8(12)$ & $11.8 \pm 33.1(71)$ & 0.020 \\
AF & $50.6 \pm 54.2(9)$ & $18.5 \pm 27.3(32)$ & 0.045 \\
Non-AF & $48.7 \pm 53.1(10)$ & $12.6 \pm 32.2(62)$ & 0.018 \\
\hline
\end{tabular}

All data are mean \pm standard deviation.

( ), number of subjects. Abbreviations as in Tables 1,3.

Table 5 FM Levels in Cases With and Without Oral Anticoagulant Therapy

\begin{tabular}{lccccc}
\hline \hline & \multicolumn{2}{c}{ With oral warfarin } & & \multicolumn{2}{c}{ Without oral warfarin } \\
\cline { 2 - 3 } \cline { 5 - 6 } & $\begin{array}{c}\text { Event }(+) \\
(5)\end{array}$ & $\begin{array}{c}\text { Event }(-) \\
(13)\end{array}$ & & $\begin{array}{c}\text { Event }(+) \\
(14)\end{array}$ & $\begin{array}{c}\text { Event }(-) \\
(81)\end{array}$ \\
\hline$P T-I N R$ & $1.4 \pm 0.5$ & $1.8 \pm 0.4$ & - & - \\
$F M(\mu \mathrm{g} / \mathrm{ml})$ & $55.9 \pm 48.1$ & $7.8 \pm 16.9 *$ & $47.4 \pm 55.6$ & $15.7 \pm 32.7 * *$ \\
\hline
\end{tabular}

All data are mean \pm standard deviation.

$* p<0.01$ vs Event $(+)$ with oral warfarin; $* * p<0.05$ vs Event $(+)$ without oral warfarin.

PT-INR, international normalized ratio of prothrombin time. Other abbreviations as in Tables 1,3.

$50.6 \pm 54.2$ vs $18.5 \pm 27.3 \mu \mathrm{g} / \mathrm{ml}, \mathrm{p}=0.045$; non-atrial fibrillation, $48.7 \pm 53.1$ vs $12.6 \pm 32.2 \mu \mathrm{g} / \mathrm{ml}, \mathrm{p}=0.018$; with oral warfarin, $55.9 \pm 48.1$ vs $7.8 \pm 16.9 \mu \mathrm{g} / \mathrm{ml}, \mathrm{p}<0.001$; without warfarin, $47.4 \pm 55.6$ vs $15.7 \pm 32.7 \mu \mathrm{g} / \mathrm{ml}, \mathrm{p}=0.036$ ) (Tables 4,5).

\section{Changes in FM Level During Acute Period}

In the 14 patients who were not on anticoagulant therapy and had no recurrent events, the serum FM level was significantly higher on day 1 (on admission) than on days 7 and 14 (day $1,20.3 \pm 13.4$ vs day $7,12.3 \pm 2.5, \mathrm{p}=0.019$, and day $14,9.7 \pm 2.4 \mu \mathrm{g} / \mathrm{ml}, \mathrm{p}=0.004)$. During the acute period, the serum FM levels on admission were the highest and then decreased to normal levels, which might reflect improvement in the patients' systemic hypercoagulable state (Fig 1).
Table 6 Cox Proportional Hazard Analysis to Predict Cerebrovascular Recurrent Events

\begin{tabular}{lccc}
\hline \hline & $\begin{array}{c}\text { Hazard } \\
\text { ratio }\end{array}$ & $95 \%$ CI & p value \\
& & & \\
\hline Univariate analysis & 1.639 & $1.281-2.180$ & 0.0002 \\
FM (per 1 SD increase) & 1.501 & $1.104-2.044$ & 0.0095 \\
CRP (per 1 SD increase) & 1.779 & $1.212-2.612$ & 0.0033 \\
PIC (per 1 SD increase) & 1.507 & $1.135-2.001$ & 0.0049 \\
D-dimer (per 1 SD increase) & 1.622 & $1.622-2.194$ & 0.0015 \\
FDP (per 1 SD increase) & 0.980 & $0.305-3.162$ & 0.9763 \\
PAI-1 (per 1 SD increase) & & & \\
Multivariate analysis & 1.516 & $1.042-2.180$ & 0.0364 \\
FM (per 1 SD increase) & 0.958 & $0.627-1.462$ & 0.8404 \\
CRP (per 1 SD increase) & 1.345 & $0.747-2.422$ & 0.3225 \\
PIC (per 1 SD increase) & 0.736 & $0.302-1.786$ & 0.4974 \\
D-dimer (per 1 SD increase) & 1.634 & $0.544-4.869$ & 0.3813 \\
FDP (per 1 SD increase) & 1.634
\end{tabular}

CI, confidence interval. Other abbreviations as in Table 3.

Table 7 Univariate Regression Analysis for Comparison of FM Levels and Other Hemostatic Markers

\begin{tabular}{lcr}
\hline \hline & Correlation coefficient & p value \\
\hline CRP $(\mathrm{mg} / \mathrm{dl})$ & 0.310 & 0.004 \\
$\operatorname{PIC}(\mathrm{ng} / \mathrm{ml})$ & 0.654 & $<0.001$ \\
$D$-dimer $(\mu \mathrm{g} / \mathrm{ml})$ & 0.494 & $<0.001$ \\
FDP $(\mu \mathrm{g} / \mathrm{ml})$ & 0.724 & $<0.001$ \\
\hline
\end{tabular}

Abbreviations as in Table 3.

Serum FM Levels and Long-Term Recurrence of Ischemic Stroke

The ability of prognostic variables to predict cerebrovascular events was examined using univariate and multivariate Cox proportional hazard analyses. Among the serum markers, high levels of FM, C-reactive protein, plasmina 2plasmin inhibitor complex, D-dimer, and fibrinogen degradation product were associated with subsequent cerebrovascular events on univariate analysis (Table 6). Serum FM levels had a significant linear relationship with the levels of C-reactive protein, plasmina 2-plasmin inhibitor complex, D-dimer, and fibrinogen degradation product (C-reactive

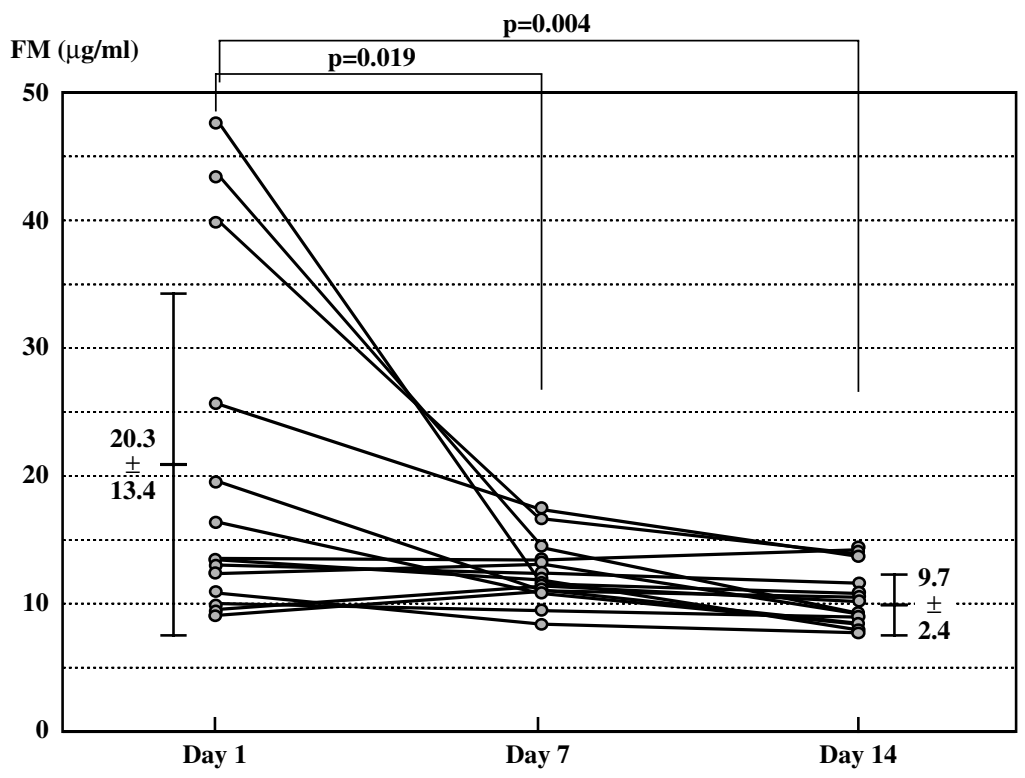

Fig 1. Changes in serum fibrin-monomer (FM) levels in 14 patients with acute ischemic stroke who were not on anticoagulants and who did not have recurrent events. During the acute period, the serum FM was at its highest level on day 1 (on admission), then decreased to normal levels, which might reflect an improvement in the patients' systemic hypercoagulable state. 
protein, $\mathrm{R}=0.310, \mathrm{p}=0.004$; plasmina 2 -plasmin inhibitor complex, $\mathrm{R}=0.654, \mathrm{p}<0.001$; D-dimer, $\mathrm{R}=0.494$, $\mathrm{p}<0.001$; fibrinogen degradation product, $\mathrm{R}=0.724, \mathrm{p}<0.001$ ) (Table 7). Therefore, these 5 independent variables were entered into the multivariate analysis, but only high serum FM level was an independent predictor of ischemic stroke recurrence with/without death (hazard ratio, 1.516 per + SD increase; 95\% confidence interval (CI), 1.042-2.180; $\mathrm{p}=$ 0.036) (Table 6). The ROC curve for the serum FM level as a predictor of cerebrovascular events at 354 days after admission in all ischemic stroke patients is shown in Fig 2; the area under the ROC curve was 0.6891. The optimal serum FM levels for predicting cerebrovascular events were determined as those with the largest sum of sensitivity plus specificity on the ROC curve; serum FM $\geq 16.5 \mu \mathrm{g} / \mathrm{ml}$ had a sensitivity of $63.2 \%$ and a specificity of $78.0 \%$ (Fig 2). Based on the ROC curve criteria, there were 32 patients with serum $F M \geq 16.5 \mu \mathrm{g} / \mathrm{ml}$ and 81 with serum $\mathrm{FM}<16.5 \mu \mathrm{g} / \mathrm{ml}$. The cerebrovascular event rates were markedly higher in patients with serum $\mathrm{FM} \geq 16.5 \mu \mathrm{g} / \mathrm{ml}$ than in those with serum $\mathrm{FM}<16.5 \mu \mathrm{g} / \mathrm{ml} \quad(\mathrm{n}=12,37.5 \%$ vs $\mathrm{n}=7,8.6 \%, \mathrm{p}<0.001)$ (Fig 3). On the Cox proportional hazards multivariate analysis, serum $F M \geq 16.5 \mu \mathrm{g} / \mathrm{ml}$ was a strong predictor for long-term cerebrovascular events (hazard ratio 5.033; 95\% CI 1.978-12.804; $\mathrm{p}<0.001)$.

\section{Discussion}

In stroke care units, levels of circulating coagulation markers, such as thrombin-antithrombin complex, D-dimer and fibrinogen degradation products, are widely accepted tools for identifying the occurrence of intracardiac thrombus. ${ }^{24-29}$ We previously reported that higher serum levels of FM, which is a precursor of the fibrin polymer and stable fibrin, reflect blood flow stagnation in the left atrial appendage, and we suggested that it may be possible to identify individuals at increased risk of cardioembolic stroke based on the serum FM levels after splashing or vanishing of the intracardiac source of the emboli! On the other hand, based on present 1-year follow up results, serum FM levels were markedly higher in patients with recurrent events than in those with no events, despite a comparable incidence of

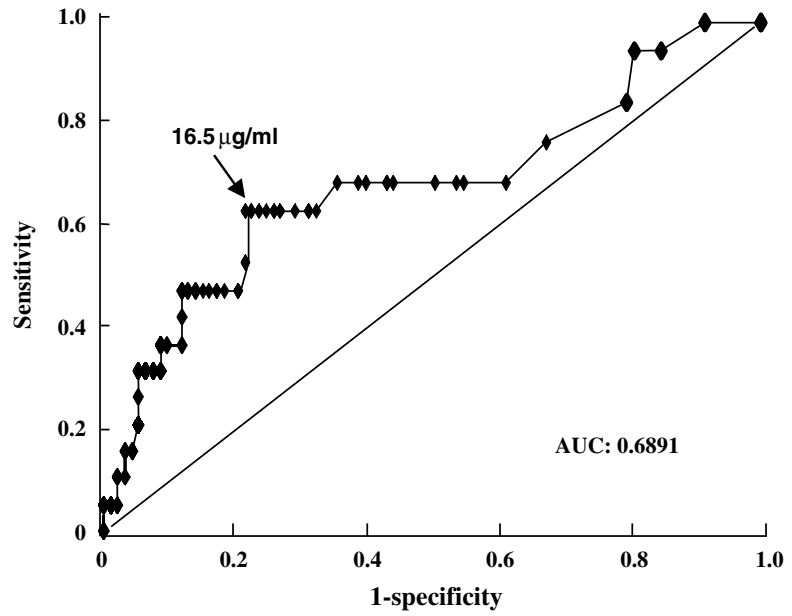

Fig 2. Receiver-operating characteristic (ROC) curve analysis. Elevated serum fibrin-monomer levels predicted cerebrovascular events in acute ischemic stroke patients at 354 days after admission. AUC, area under the ROC curve.

intracardiac thrombus formation in the 2 groups. Thus, patients with serum $\mathrm{FM} \geq 16.5 \mu \mathrm{g} / \mathrm{ml}$ had significantly higher rates of recurrent event $(37.5 \%)$ than those with serum FM $<16.5 \mu \mathrm{g} / \mathrm{ml}(8.6 \%)$. Furthermore, $6 \pm 1$ days after initial admission, FM levels were significantly higher in patients with recurrent events than in those with no events, regardless of the presence of cardioembolic stroke or atrial fibrillation. The FM level also had a close linear relationship with that of C-reactive protein, plasmina 2-plasmin inhibitor complex, D-dimer, or fibrinogen degradation product. This is the first study to demonstrate that, among patients with all stroke subtypes, an elevated serum FM level is an independent predictor for long-term cerebrovascular recurrent events, as well as the serum hemostatic markers previously reported.

Fassbender et al reported that the intravenous infusion of recombinant tissue plasminogen activator induced a massive response of the coagulation activation markers, which peaked after $1-3 \mathrm{~h}$ and persisted for up to $72 \mathrm{~h} 30$ Similar

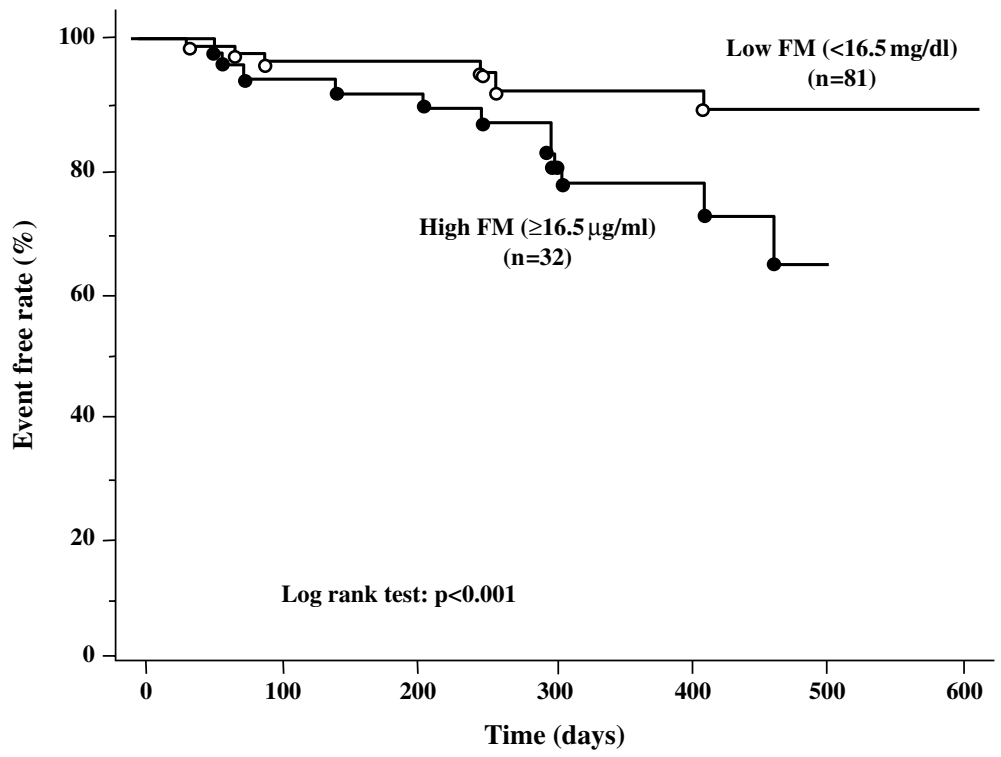

Fig 3. Kaplan-Meier analysis of cerebrovascular event-free survival in patients with acute ischemic stroke stratified into 2 groups based on the serum fibrinmonomer (FM) levels. The cerebrovascular event rates were markedly higher in patients with $\mathrm{FM} \geq 16.5 \mu \mathrm{g} / \mathrm{ml}$ (37.5\%) than in patients with $\mathrm{FM}<16.5 \mu \mathrm{g} / \mathrm{ml}(8.6 \%$, $\mathrm{p}<0.001)$. 
results were noted in the present study, because serum FM concentrations increased within $1 \mathrm{~h}$ after initiation of thrombolysis, peaked at $3 \mathrm{~h}$, and had declined toward baseline levels at 3 days $(<10 \mu \mathrm{g} / \mathrm{ml}$ before treatment and 30 $40 \mu \mathrm{g} / \mathrm{ml}$ at $3 \mathrm{~h}$ after thrombolysis) $)^{30}$ On the other hand, few reports have examined the natural time course of the inflammatory and coagulation parameters in the early stage of stroke. Based on those, high-sensitive C-reactive protein and fibrinogen levels are at their highest levels 1-3 days after stroke onset 31,32 It is important to clarify the changes in the circulating FM levels that occur in ischemic stroke patients during the acute period, so we examined the serum FM level in 14 patients who received no anticoagulant therapy and had no recurrent events. We found that, during the acute period, the serum FM level was highest on admission and then decreased towards normal levels within 7 days, which may reflect an improvement in the patients' systemic hypercoagulable state. Thus, it is possible that persistent elevation of serum FM levels during the acute phase in hospitalized ischemic stroke patients reflects a persistent hypercoagulable state that may be a predictor of recurrent ischemic stroke.

It is well known that serum FM levels are suppressed by therapeutic doses of warfarin.5,29 Furthermore, the Japan Stroke Society has proposed guidelines for preventing ischemic stroke in Japanese patients older than 70 years of age with prior cardioembolic stroke and nonvalvular atrial fibrillation; the guidelines suggest that dose-adjusted warfarin sodium should be given (international normalized ratio of prothrombin time (PT-INR) of 1.6-2.6) unless there is a specific contraindication to warfarin! 33,34 In the present study, 5 of 18 cases who received oral warfarin treatment developed an ischemic stroke during follow-up. Patients with no events tended to have higher PT-INR values than patients with recurrent events. On the other hand, regardless of oral warfarin treatment, the serum FM levels were significantly decreased in patients with no events as compared with those with recurrent events. Therefore, the measurement of serum FM levels in acute ischemic stroke patients is useful for predicting long-term cerebrovascular events, even in those given anticoagulant therapy.

\section{Study Limitations}

First, the number of patients with recurrent cerebrovascular events in the high serum FM group $(F M \geq 16.5)$ was small. Second, the effects on the serum FM levels of intravenous infusion of thrombolytic agents were not examined. Third, serum FM levels during the follow-up period were not examined, so we could not clarify a direct causal relation between recurrent events and higher levels of this new marker. Finally, transesophageal echocardiography was not performed during follow-up, so we could not determine whether the long-term prognosis was affected by the disappearance of intracardiac thrombus and/or aortic mobile plaques in patients with and without recurrent cerebrovascular events. Further studies with a larger number of subjects with various stroke subtypes are needed to confirm the close association between higher serum FM levels and long-term prognosis.

\section{Conclusion}

Our present study found that it may be possible to identify individuals at increased risk of recurrent stroke based on serum coagulation marker levels measured $6 \pm 1$ days after onset of acute ischemic stroke. The persistent elevation of serum FM levels in hospitalized ischemic stroke patients may be associated with a persistent systemic hypercoagulable state and long-term ischemic stroke recurrence with/ without death, as well as the serum coagulation markers previously reported.

\section{References}

1. Okuyama H, Hirono O, Liu L, Takeishi Y, Kayama T, Kubota I. Higher levels of serum fibrin-monomer reflect hypercoagulable state and thrombus formation in the left atrial appendage in patients with acute ischemic stroke. Circ J 2006; 70: 971-976.

2. Blomback B, Bark N. Fibrinopeptide and fibrin gel structure. Biophys Chem 2004; 112: 147-151.

3. Dempfle CE. The use of soluble fibrin in evaluating the acute and chronic hypercoagulable state. Thromb Haemost 1999; 82: 673-683.

4. Hong M, Wei W, Li H, Yang R, Yang Y. Association of fibrin monomer polymerization function, cerebrovascular risk factors and ischemic cerebrovascular disease in old people. J Huazhong Univ Sci Technolog Med Sci 2003; 23: 131-133.

5. Deguchi K, Deguchi A, Wada H, Murashima S. Study of cardiovascular risk factors and hemostatic molecular markers in elderly persons. Semin Thromb Hemost 2000; 26: 23-27.

6. Takano K, Yamaguchi T, Kato H, Omae T. Activation of coagulation in acute cardioembolic stroke. Stroke 1991; 22: 12-16.

7. Takano K, Yamaguchi T, Uchida K. Markers of a hypercoagulable state following acute ischemic stroke. Stroke 1992; 23: 194-198.

8. Soda T, Nakayasu H, Meda M, Kusumi M, Kowa H, Awaki E, et al. Stroke recurrence within the first year following cerebral infarction: Tottori University Lacunar Infarction Prognosis Study (TULIPS). Acta Neurol Scand 2004; 110: 343-349.

9. Yokota C, Minematsu K, Hasegawa Y, Yamaguchi T. Long-term prognosis, by stroke subtypes, after a first-ever stroke: A hospitalbased study over a 20-year period. Cerebrovasc Dis 2004; 18: 111 116.

10. National Institute of Neurological Disorders and Stroke. Special report: Classification of cerebrovascular diseases III. Stroke 1990; 21: $637-676$.

11. Brott T, Adams HP Jr, Olinger CP, Marler JR, Barsan WG, Biller J, et al. Measurements of acute cerebral infarction: A clinical examination scale. Stroke 1989; 20: 864-870.

12. Hanley JA, McNeil BJ. The meaning and use of the area under a receiver operating characteristic (ROC) curve. Radiology 1982; 143: $29-36$.

13. Blum A, Reisner S, Farbstein Y. Transesophageal echocardiography (TEE) vs transthoracic echocardiography (TTE) in assessing cardiovascular sources of emboli in patients with acute ischemic stroke. Med Sci Monit 2004; 10: 521-523.

14. Narumiya T, Sakamaki T, Sato Y, Kanmatsuse K. Relationship between left atrial appendage function and left atrial thrombus in patients with nonvalvular chronic atrial fibrillation and atrial flutter. Circ J 2003; 67: 68-72.

15. Oyama R, Murata K, Tanaka N, Takai A, Ueda K, Liu J, et al. Is the ratio of transmitral peak E-wave velocity to color flow propagation velocity useful for evaluating the severity of heart failure in atrial fibrillation? Circ J 2004; 68: $132-138$.

16. Fatkin D, Kuchar DL, Thorburn CW, Feneley MP. Transesophageal echocardiography before and during direct current cardioversion of atrial fibrillation: Evidence for "atrial stunning" as a mechanism of thromboembolic complications. J Am Coll Cardiol 1994; 23: $307-$ 316.

17. Fatkin D, Feneley MP. Patterns of Doppler-measured blood flow velocity in the normal and fibrillating human left atrial appendage. Am Heart J 1996; 132: 995-1003.

18. Amarenco P, Cohen A, Tzourio C, Bertrand B, Hommel M, Besson $\mathrm{G}$, et al. Atherosclerotic disease of the aortic arch and the risk of ischemic stroke. N Engl J Med 1994; 331: 1474-1479.

19. Amarenco P, Duyckaerts C, Tzourio C, Henin D, Bousser MG, Hauw JJ. The prevalence of ulcerated plaques in the aortic arch in patients with stroke. N Engl J Med 1992; 326: 221 - 225.

20. Pignoli P, Tremoli E, Poli A, Oreste P, Paoletti R. Intimal plus medial thickness of the arterial wall: A direct measurement with ultrasound imaging. Circulation 1986; 74: 1399-1406.

21. European Carotid Surgery Trialists Collaborative Group. Randomised trial of endarterectomy for recently symptomatic carotid stenosis: Final results of the MRC European Carotid Surgery Trial (ECST). Lancet 1998; 351: 1379-1387. 
22. U-King-Im JM, Trivedi RA, Cross JJ, Higgins NJ, Hollingworth W, Graves M, et al. Measuring carotid stenosis on contrast-enhanced magnetic resonance angiography: Diagnostic performance and reproducibility of 3 different methods. Stroke 2004; 35: 2083-2088.

23. Hamano A, Umeda M, Ueno Y, Tanaka S, Mimuro J, Sakata Y. Latex immunoturbidimetric assay for soluble fibrin complex. Clin Chem 2005; 51: $183-188$

24. Di Napoli M, Papa F, Bocola V. Prognostic influence of increased Creactive protein and fibrinogen levels in ischemic stroke. Stroke 2001; 32: $133-138$

25. Urabe T, Tanaka R, Noda K, Mizuno Y. Anticoagulant therapy with a selective thrombin inhibitor for acute cerebral infarction: Usefulness of coagulation markers for evaluation of efficacy. J Thromb Thrombolysis 2002; 13: 155-160.

26. Ageno W, Finazzi S, Steidl L, Biotti MG, Mera V, Melzi D’Eril G, et al. Plasma measurement of D-dimer levels for the early diagnosis of ischemic stroke subtypes. Arch Intern Med 2002; 162: 2589-2593.

27. Vene N, Mavri A, Kosmelj K, Stegnar M. High D-dimer levels predict cardiovascular events in patients with chronic atrial fibrillation during oral anticoagulant therapy. Thromb Haemost 2003; 90: $973-$ 975.

28. Kelly J, Rudd A, Lewis RR, Coshall C, Parmar K, Moody A, et al. Screening for proximal deep vein thrombosis after acute ischemic stroke: A prospective study using clinical factors and plasma D- dimers. J Thromb Haemost 2004; 2: 1321 - 1326.

29. Nozawa T, Inoue H, Izawa A, Okumura K, Jong-dae L, Shimizu A, at al. Effects of anticoagulation intensity on hemostatic markers in patients with non-valvular atrial fibrillation. Circ J 2004; 68: 29-34.

30. Fassbender K, Dempfle CE, Mielke O, Schwartz A, Daffertshofer M, Eschenfelder C, et al. Changes in coagulation and fibrinolysis markers in acute ischemic stroke treated with recombinant tissue plasminogen activator. Stroke 1999; 30: 2101-2104.

31. Palasik W, Fiszer U, Lechowicz W, Czartoryska B, Krzesiewicz M, Lugowska A. Assessment of relations between clinical outcome of ischemic stroke and activity of inflammatory processes in the acute phase based on examination of selected parameters. Eur Neurol 2005; 53: $188-193$.

32. Tamam Y, Iltumur K, Apak I. Assessment of acute phase proteins in acute ischemic stroke. Tohoku J Exp Med 2005; 206: 91-98.

33. Yamaguchi T. Optimal intensity of warfarin therapy for secondary prevention of stroke in patients with nonvalvular atrial fibrillation: A multicenter, prospective, randomized trial: Japanese Nonvalvular Atrial Fibrillation-Embolism Secondary Prevention Cooperative Study Group. Stroke 2000; 31: 817-821.

34. Yasaka M, Minematsu K, Yamaguchi T. Optimal intensity of international normalized ratio in Warfarin therapy for secondary prevention of stroke in patients with non-valvular atrial fibrillation. Intern Med 2001; 40: 1183-1188. 